[white paper]

\title{
Detectando neutrinos fantasmagóricos: minúsculos mensageiros do universo
}

\author{
Colaboração Ciência Aberta ${ }^{1}$ \\ 8 de Dezembro de 2021
}

\begin{abstract}
Resumo
Este artigo é uma versão traduzida do texto original [1], por meio do qual iremos apresentar como os gigantes detectores nos ajudam a decodificar as informações sobre a composição e história das estrelas que são transmitidas pelos neutrinos.
\end{abstract}

palavras-chave: neutrinos, partículas, detectores, decaimento radioativo

A versão mais atualizada deste artigo está disponível em

https://osf.io/y7xjk/download

https://zenodo.org/record/5761542

\section{Preâmbulo}

1. Este artigo foi elaborado a partir de [1], seguindo as diretrizes da licença Creative Commons [2].

2. A referência [1], em português, pode ser lida em https://bit.1y/31E1QqS.

${ }^{1}$ Todos os autores com suas afiliações aparecem no final deste artigo. 


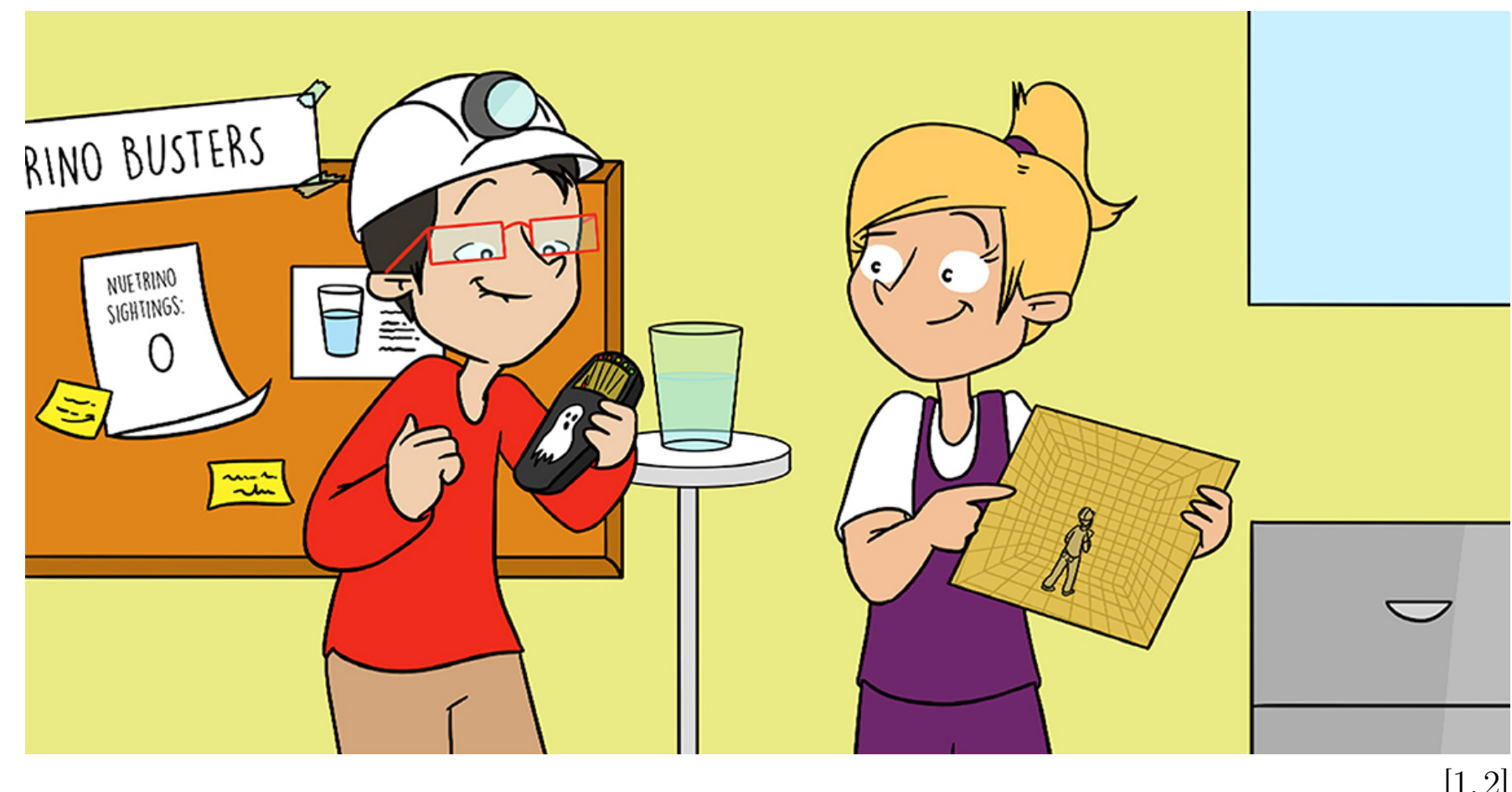

\section{Glossário}

3. Aceleradores: São máquinas nas quais partículas carregadas, como elétrons ou prótons, são aceleradas quase à velocidade da luz. Os cientistas podem colidir feixes muito intensos de tais particulas com alvos para produzir outras partículas subatômicas, incluindo neutrinos energéticos.

4. Antimatéria: Cada tipo de partícula carregada de matéria tem uma contraparte com carga oposta. Essas partículas idênticas, mas com cargas opostas, são a antimatéria (ou antipartículas). Por exemplo, a contraparte de antimatéria de um múon (com carga negativa) é um antimúon (com carga positiva). Os neutrinos não têm carga, mas também têm antipartículas; compreender a natureza desses antineutrinos é um dos mistérios mais importantes da física.

5. Argônio líquido: É um gás inerte que forma $1 \%$ da atmosfera da Terra. Torna-se líquido a $-186^{\circ} \mathrm{C}$ e tem a aparência límpida de água. É bom para detectar neutrinos porque a ionização dura o suficiente para ser detectada. 
6. Big Bang: É uma abreviatura para o evento que deu início ao universo a partir de um único ponto preenchido com um estado de matéria quente e densa há cerca de 14 bilhões de anos. Todas as partículas e matéria que vemos hoje, incluindo todas as galáxias, estrelas, planetas e mais, formaram-se à medida que este estado semelhante a um ponto se expandia e resfriava.

7. Decaimento radioativo: Os núcleos de muitos átomos são instáveis e, com o tempo, eles se separam, liberando partículas energéticas, como raios alfa, beta e gama. Este processo de separação é denominado decaimento radioativo.

8. Ionização: Ocorre quando as partículas energéticas eliminam os elétrons dos átomos. Os resultados são íons carregados positivamente e elétrons livres.

9. Reações nucleares: Acontecem quando os núcleos atômicos reagem entre si formando outros núcleos. No Sol, os núcleos de hidrogênio (prótons) se combinam para formar núcleos de hélio e liberar energia - calor e luz solar.

10. Tipos de neutrinos: Os neutrinos vêm em três tipos, nomeados em homenagem a diferentes tipos de partículas carregadas que produzem quando interagem com a matéria comum. As três partículas fundamentais com carga negativa são o elétron, o múon e a partícula tau. Eles são idênticos em todos os aspectos, exceto que o múon é 200 vezes mais pesado que o elétron e o tau é 3.500 vezes mais pesado.

\section{Introdução}

11. Os neutrinos são partículas minúsculas e subatômicas que quase parecem fantasmas.

12. Trilhões de neutrinos passam por nós a cada segundo sem deixar rastros! A maioria vindo do nosso Sol. 
13. Ao contrário da luz solar, que podemos ver facilmente, os neutrinos são muito difíceis de detectar, pois não costumam interagir com materiais comuns.

14. Para "vê-los", temos que construir detectores realmente grandes e bloquear os sinais de quaisquer outras partículas.

15. Os cientistas fazem isso construindo detectores de neutrinos no subsolo.

16. Os neutrinos vêm principalmente das reações nucleares, que ocorrem quando os núcleos atômicos reagem entre si formando outros núcleos.

17. Para "ver" os neutrinos, os cientistas constroem detectores realmente grandes e sensíveis, muitas vezes nas profundezas do solo.

18. A matéria que constitui a Terra ajuda a proteger os sinais de outras partículas, de modo que os sinais das raras interações dos neutrinos tenham chance de serem detectados.

19. Os detectores gigantes estão ajudando os cientistas a captar as "mensagens" que essas partículas fantasmagóricas carregam.

20. Quando os cientistas decodificam as mensagens, eles aprendem sobre a conexão entre os neutrinos e a composição e história das estrelas, galáxias e do universo.

\section{O que é um neutrino?}

21. Os neutrinos são partículas muito leves sem carga elétrica, emitidos quando os núcleos atômicos instáveis decaem.

22. Tal decaimento radioativo (processo de separação) acontece ao nosso redor. 
23. Os núcleos de muitos átomos são instáveis e, com o tempo, eles se separam, liberando partículas energéticas, como os raios alfa, beta e gama.

24. Os minerais nas rochas e até o potássio nas bananas se decompõem para produzir neutrinos (veja a Fig. 1).

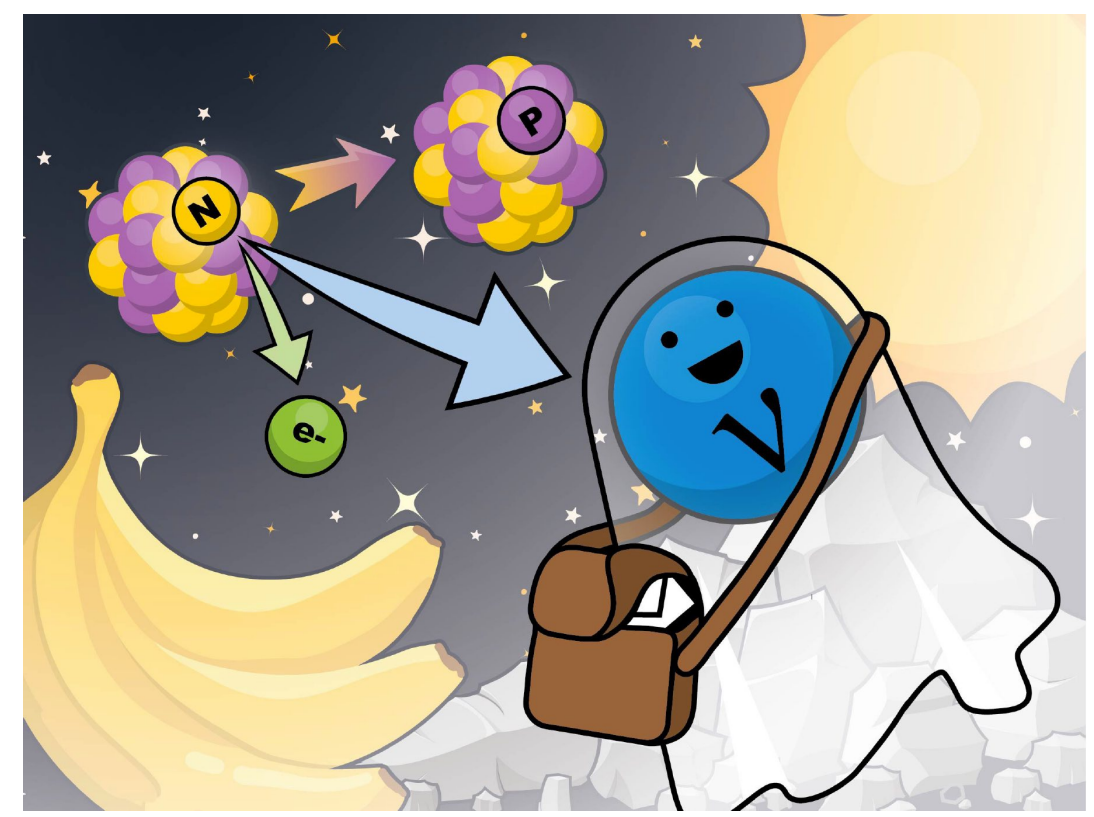

Figura 1: Decaimento de um átomo radioativo (potássio-40) - que é encontrado em bananas e tem 40 prótons $(p)$ e nêutrons $(n)$ em seu núcleo - em cálcio-40, mais um elétron $\left(e^{-}\right)$e uma "partícula mensageira fantasmagórica" chamada neutrino (pronuncia-se "ni" a letra grega $\nu$ ). Compreender o comportamento dos neutrinos pode ajudar a revelar segredos importantes do universo. Crédito: Tiffany Bowman, Laboratório Nacional de Brookhaven [1].

25. Um número muito maior de neutrinos que chegam até nós vem das reações nucleares que ocorrem no Sol do que de qualquer de outra fonte.

26. Não importa qual seja a fonte, os neutrinos são completamente inofensivos porque não se unem nem interagem com muita coisa.

27. Eles fluem do Sol e do espaço sideral e passam direto pela matéria 
comum - até mesmo nossos próprios corpos e a própria Terra - sem que nunca saibamos.

28. Por isso é que dizemos que os neutrinos se parecem um pouco com fantasmas - estão ali, mas são invisíveis.

29. Como os neutrinos carregam informações sobre o que está acontecendo dentro do coração das estrelas e galáxias, os cientistas querem saber muito mais sobre eles.

30. Eles podem até nos ajudar a entender o que estava acontecendo quando nosso universo se formou há quase 14 bilhões de anos!

\section{Como pegar uma partícula fantasmagórica}

31. Os neutrinos raramente interagem com a matéria comum, por isso são muito difíceis de detectar.

32. Se você colocar um copo d'água sobre uma mesa, um trilhão de neutrinos passarão por ele a cada segundo.

33. A maioria dessas partículas misteriosas se move sem fazer nenhum som ou deixar rastros.

34. Mas ocasionalmente, muito raramente, como uma vez a cada dez milhões de trilhões de vezes, um neutrino atinge um dos átomos que constituem uma molécula de água.

35. Essa interação rara pode gerar um minúsculo flash de luz ou deixar alguma carga elétrica gratuita.

36. No entanto, o flash gerado é muito fraco para seus olhos verem.

37. Mas os cientistas podem construir detectores muito sensíveis para captar esses sinais fracos. 
38. A eletrônica dentro dos detectores amplifica os sinais para tornar visiveis os "fantasmas" invisiveis!

39. Mas esperar que ocorra uma interação de neutrino de "um em dez milhões de trilhões" pode levar muito tempo.

40. Para capturar neutrinos suficientes para aprender qualquer coisa sobre eles, os cientistas precisam de um "copo d'água" maior - tanques enormes com milhões de galões! E eles têm que colocar os enormes tanques detectores no subsolo. Isso porque os neutrinos não são as únicas partículas voando para a Terra. Muitas outras partículas energéticas, conhecidas como raios cósmicos, também fluem do espaço sideral.

41. Cada uma dessas partículas de raios cósmicos pode causar uma interação visível nos detectores. Se o tanque detector estivesse acima do solo, milhões de interações de raios cósmicos facilmente abafariam os raros sinais do neutrino.

42. Mas com o detector no subsolo, os raios cósmicos são interrompidos por interações com os átomos da Terra, enquanto os neutrinos passam direto para deixar sua marca no detector.

\section{Diferentes detectores e tipos de neutrinos}

43. Os neutrinos têm uma grande variedade de energias.

44. Essa variação pode levar a um minúsculo flash de luz ou um flash muito brilhante em detectores cheios de água.

45. Os neutrinos também vêm em três tipos diferentes, chamados sabores.

46. Os cientistas aprenderam a construir detectores adequados para cada tipo de neutrino e sua enorme gama de energias. 
47. A interação de cada tipo diferente de neutrino produz um tipo diferente de partícula carregada negativamente.

48. Um neutrino de elétron produz um elétron (bem simples, certo?).

49. Os outros dois tipos de neutrino recebem o nome de partículas subatômicas diferentes e mais pesadas: um neutrino de múon produz uma partícula de múon; e um neutrino tau produz uma partícula tau.

50. Também há versões de antimatéria dos três tipos de neutrino.

51. Os antineutrinos são exatamente iguais aos neutrinos de matéria comum, exceto que produzem partículas carregadas positivamente no detector.

52. Os cientistas sabem diferenciar entre os diferentes tipos de neutrinos e antineutrinos porque cada um deixa um padrão diferente no detector.

53. Por exemplo, os múons deixam rastros retos, os elétrons parecem chuvas e as partículas de tau decaem rapidamente para produzir vários rastros retos.

54. Usando os diferentes padrões, os cientistas podem decodificar os sabores de neutrinos e a mensagem oculta transmitida por cada partícula fantasmagórica.

\section{Eletrônicos sensíveis tiram fotos em 3D}

55. Uma equipe de cientistas está atualmente construindo um novo detector de neutrino gigante, no subsolo, em Dakota do Sul, nos Estados Unidos.

56. Este experimento é conhecido como Deep Underground Neutrino Experiment (DUNE).

57. Seu detector será preenchido com argônio líquido. 


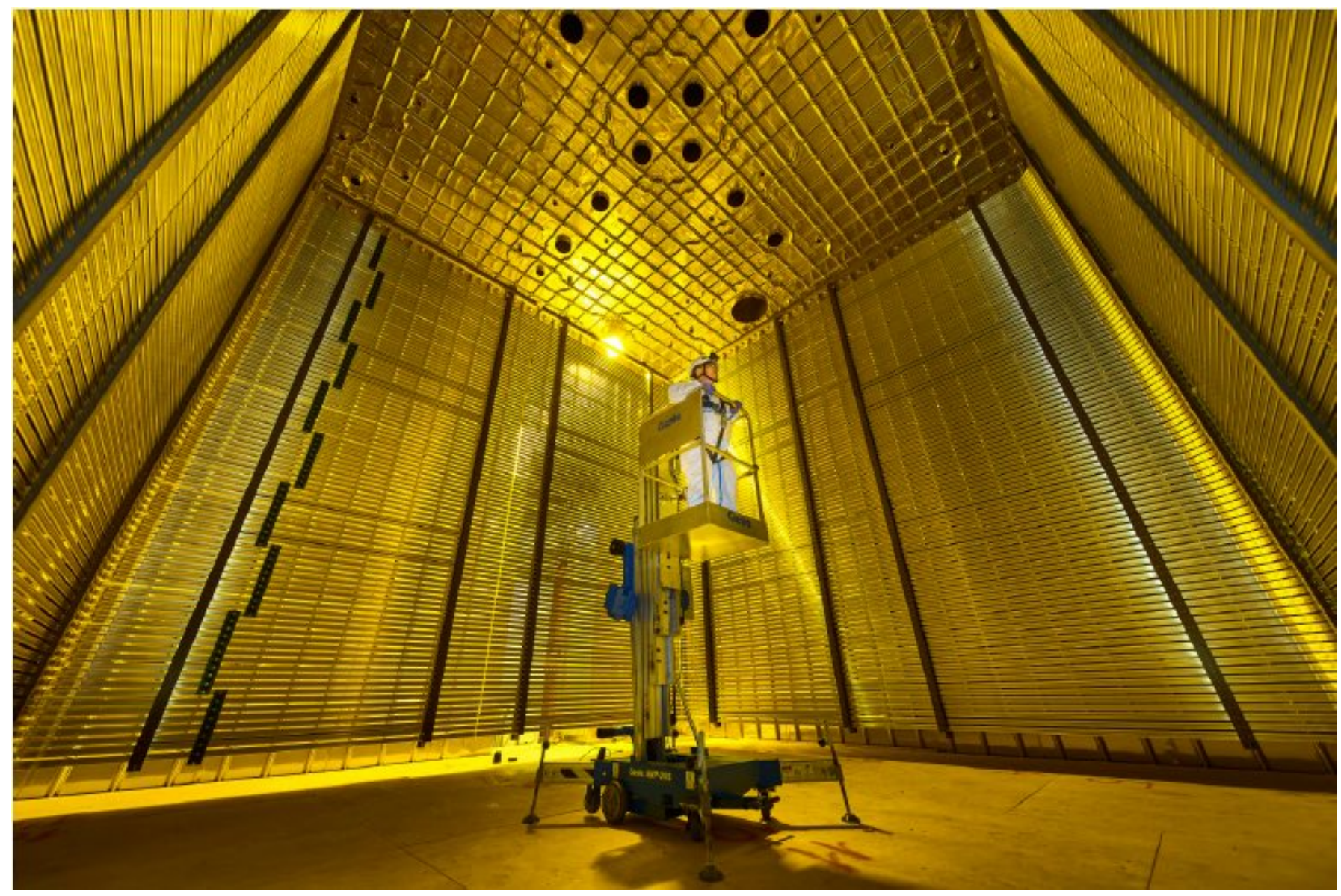

Figura 2: Um cientista está dentro do detector ProtoDUNE no laboratório CERN da Europa antes que ele fosse preenchido com argônio líquido puro frio $\left(-186^{\circ} \mathrm{C}\right)$. O cientista está inspecionando a superfície interna, que está em uma caixa isolada feita de aço inoxidável muito limpo. Quando o detector está cheio e operando, essas superfícies são energizadas com alta voltagem para fazer com que as partículas carregadas produzidas pela ionização do argônio líquido flutuem e sejam captadas por componentes eletrônicos sensíveis para que os cientistas possam registrá-las. Crédito: Fermi National Accelerator Laboratory [1]. 
58. O gás argônio representa apenas 1/100 de nossa atmosfera, mas os cientistas podem coletá-lo para fazer argônio líquido muito puro.

59. Este líquido super frio $\left(-186^{\circ} \mathrm{C}\right)$ torna mais fácil detectar os caminhos das partículas carregadas produzidas por interações de neutrinos.

60. Isso ocorre porque, à medida que as partículas carregadas rapidamente se movem através do argônio líquido, elas ionizam os átomos de argônio em seu caminho.

61. Essa ionização permite que os rastros que eles deixam apareçam como "raios".

62. Podemos "ver" neutrinos? (https://youtu.be/3wn_pyU44Ck) Este vídeo mostra os rastros de muitas partículas de raios cósmicos passando pelo detector ProtoDUNE. Os dados foram utilizados para testar o desempenho do detector. As cores correspondem à intensidade da ionização no argônio líquido (o vermelho é menos e o azul é mais intenso). A ionização é movida pela aplicação de um poderoso campo elétrico ao detector. A imagem 3D foi criada, analisando e combinando os sinais eletrônicos de milhares de fios nas paredes que agem como pixels em uma câmera digital. Crédito: Chao Zhang, Laboratório Nacional de Brookhaven [1].

63. Construir um detector de argônio líquido frio é um grande desafio.

64. Para garantir que esse novo design funcione, a equipe internacional recentemente construiu e testou uma versão menor, conhecida como ProtoDUNE (veja a Fig. 2).

65. Eles dispararam diferentes tipos de partículas por meio desse detector no Laboratório Europeu de Física de Partículas do Conselho Europeu de Pesquisa Nuclear (CERN).

66. Equipamentos eletrônicos cuidadosamente projetados registraram os sinais e os computadores transformaram essas medições em belas imagens 3D dos caminhos percorridos pelas partículas. 


\section{Mensageiros do Sol, atmosfera, reatores e ace- leradores}

67. Nos últimos 50 anos, os cientistas ficaram melhores na detecção de neutrinos.

68. Eles os mediram vindos do Sol, de colisões de raios cósmicos com átomos na atmosfera da Terra e de reatores nucleares que produzem eletricidade (veja a Fig. 3).

69. Eles também aprenderam a fazer neutrinos muito energéticos em aceleradores de partículas de alta potência.

70. Cada tipo de fonte produz diferentes sabores de neutrinos com diferentes energias.

71. Contando cuidadosamente os neutrinos de cada sabor a várias distâncias dessas fontes, os cientistas fizeram duas descobertas notáveis sobre os neutrinos.

72. Primeiro, eles descobriram que os neutrinos dos três tipos diferentes se transformam uns nos outros à medida que viajam pelo espaço!

73. Em outras palavras, as mensagens que os neutrinos carregam mudam enquanto voam.

74. Em segundo lugar, eles descobriram que os neutrinos têm uma massa muito pequena!

75. Cada partícula de neutrino pesa menos de 1 milionésimo da massa de um elétron.

76. O primeiro experimento que detectou neutrinos solares com sucesso, por Raymond Davis do Brookhaven National Laboratory na década de 1960, encontrou uma surpresa: muitos dos neutrinos que os cientistas esperavam detectar estavam de alguma forma "perdidos". 


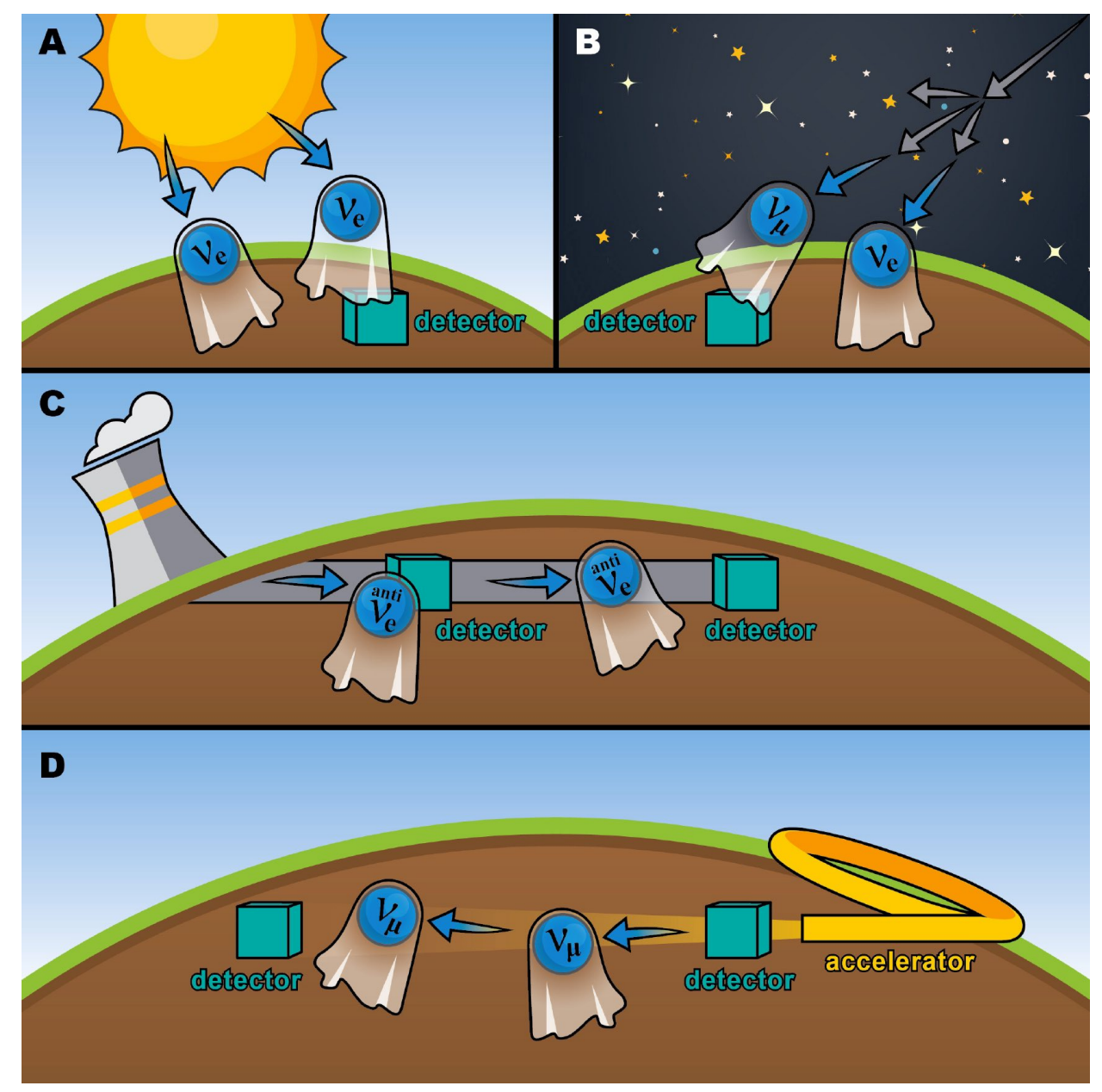

Figura 3: As quatro fontes de neutrinos utilizadas para os experimentos. (A) O Sol produz neutrinos de elétrons $\left(\nu_{e}\right)$. (B) Neutrinos de dois tipos, múon $\left(\nu_{\mu}\right)$ e elétron $\left(\nu_{e}\right)$, são produzidos por colisões de raios cósmicos de alta energia com átomos na atmosfera terrestre. (C) Os reatores nucleares emitem neutrinos antielétrons $\left(\right.$ anti $\nu_{e}$ ). (D) Aceleradores de prótons de alta energia produzem um feixe de neutrinos do múon $\left(\nu_{\mu}\right)$, que é direcionado através da Terra. Os detectores são colocados em distâncias diferentes das fontes. Crédito: Tiffany Bowman, Laboratório Nacional de Brookhaven [1]. 
77. Os cientistas projetaram seu detector para receber apenas um tipo de neutrino - neutrinos de elétrons gerados no centro do Sol.

78. Eles poderiam calcular exatamente quantos neutrinos de elétrons deveriam ser detectados.

79. Mas apenas cerca de um terço dos neutrinos de elétrons esperados apareceu no detector.

80. Por meio de experimentos subsequentes, os cientistas finalmente descobriram o motivo por trás desse mistério: alguns dos neutrinos do elétron se transformaram em um dos outros dois sabores (múon ou tau) durante sua jornada do Sol.

81. A descoberta de Davis sobre o "déficit de neutrino solar" foi, em princípio, muito controversa.

82. Ela teve que ser testada por outros experimentos, que usaram neutrinos atmosféricos, neutrinos do reator e neutrinos do acelerador.

83. Em todos esses experimentos, os cientistas descobriram que os sabores de neutrinos estavam "desaparecendo" - transformando-se em outros sabores a longa distância.

84. O novo experimento DUNE nos Estados Unidos e o experimento HyperKamiokande no Japão revelarão mais detalhes sobre o comportamento de mudança de forma de neutrinos e antineutrinos.

85. Se os cientistas encontrarem uma diferença entre como os neutrinos e antineutrinos se transformam, isso pode resolver um dos mistérios mais importantes do universo: por que o universo é feito apenas de matéria e não de antimatéria.

86. Os cientistas acham que tanto a matéria quanto a antimatéria foram criadas em quantidades iguais no Big Bang. 
87. Quantidades iguais desses dois opostos deveriam ter destruído um ao outro, deixando apenas luz! Portanto, a existência de apenas matéria hoje é evidência de que houve um pequeno excesso de matéria.

88. É possível que a diferença entre neutrinos e antineutrinos tenha causado esse pequeno excesso à medida que o universo se expandia e esfriava.

89. Se isso for verdade, devemos agradecer aos neutrinos pelo universo que temos hoje, cheio de todas as coisas visíveis ao nosso redor, incluindo rochas, plantas, animais e pessoas!

\section{Ciência Aberta}

O arquivo latex para este artigo, juntamente com outros arquivos suplementares, estão disponíveis em [3]. Seja coautor(a) deste artigo, envie sua contribuição para mplobo@uft.edu.br.

\section{Consentimento}

Os autores concordam com [4].

\section{Como citar este artigo?}

https://doi.org/10.31219/osf.io/y7xjk

https://zenodo.org/record/5761542

\section{Licença}

CC-By Attribution 4.0 International [2] 


\section{Referências}

[1] Diwan M and McNulty Walsh K (2020) "Detecting Ghostlike Neutrinos: Tiny Messengers From the Universe." Front. Young Minds. 8:45. https://doi.org/10.3389/frym.2020.00045

[2] CC. Creative Commons. CC-By Attribution 4.0 International. https://creativecommons .org/licenses/by/4.0

[3] Lobo, Matheus P. "Open Journal of Mathematics and Physics (OJMP)." OSF, 21 Apr. 2020.

https://doi.org/10.17605/osf .io/6hzyp

[4] Lobo, Matheus P. "Simple Guidelines for Authors: Open Journal of Mathematics and Physics." OSF Preprints, 15 Nov. 2019.

https://doi.org/10.31219/osf .io/fk836

\section{Colaboração Ciência Aberta}

\section{Márcio Guimarães de Sousa ${ }^{1}$}

(autor principal, marcio.guimaraes@uft.edu.br)

https://orcid.org/0000-0003-1064-4793

Matheus Pereira Lobo ${ }^{1,2}$

https://orcid.org/0000-0003-4554-1372

${ }^{1}$ Universidade Federal do Tocantins (Brasil)

${ }^{2}$ Universidade Aberta (UAb, Portugal) 